El evat i on of fecal eosi nophi I-der i ved neur ot oxi $n$ i $n$ inf ant $s$ wi th food pr ot ei $n$ - i nduced ent er ocol i t i s syndrome

\begin{tabular}{|l|l|}
\hline 著者 & $\begin{array}{l}\text { Wada Tai zo, Toma Tonøko, Mir aoka Nasahi ro, } \\
\text { Nat suda Yusuke, Yachi e Aki hi ro }\end{array}$ \\
\hline $\begin{array}{l}\text { j our nal or } \\
\text { publ i cat i on ti t l e }\end{array}$ & Pedi at r i c Al I er gy and I mmunol ogy \\
\hline vol une & 25 \\
\hline number & 6 \\
\hline page r ange & $617-619$ \\
\hline year & 2014 10-01 \\
\hline URL & ht t p: //hdl . handl e. net /2297/39698 \\
\hline
\end{tabular}


Manuscript category: Letter to the Editor

\section{Elevation of fecal eosinophil-derived neurotoxin in infants with food protein-induced enterocolitis syndrome}

Taizo Wada, Tomoko Toma, Masahiro Muraoka, Yusuke Matsuda, and Akihiro Yachie

\section{Institutional affiliations:}

Department of Pediatrics, School of Medicine, Institute of Medical, Pharmaceutical and Health Sciences, Kanazawa University, Kanazawa, Japan.

Correspondence to: Taizo Wada, $\mathrm{MD}, \mathrm{PhD}$

Department of Pediatrics, School of Medicine, Institute of Medical, Pharmaceutical and Health Sciences, Kanazawa University 13-1 Takaramachi, Kanazawa 920-8641, Japan Phone: +81-76-265-2313

Fax: +81-76-262-1866

E-mail: taizo@staff.kanazawa-u.ac.jp

Short title: Elevation of fecal EDN in FPIES

Key words: food protein-induced enterocolitis syndrome, oral food challenge, stool, eosinophil-derived neurotoxin, calprotectin 
To the Editor,

Food protein-induced enterocolitis syndrome (FPIES) is an uncommon, nonimmunoglobulin E (IgE)-mediated food allergy that usually occurs in young infants (1). Patients with FPIES exhibit profuse vomiting, lethargy, pallor and diarrhea, which typically occur 1 to $4 \mathrm{~h}$ after the ingestion of the causative food. The most common causative foods are cow's milk and soy. FPIES is usually diagnosed based on medical history, response to an elimination diet, and an oral food challenge. An oral food challenge remains the gold standard test for all food allergies including FPIES, although it carries a risk for life-threatening reactions.

Skin-prick test and specific IgE have been reported to be negative in the majority of patients with FPIES at diagnosis (1). Diagnostic value of atopy patch testing remains unclear, although patients with FPIES may show positive patch tests with the specific allergen (1). A frequent sensitization to causative foods can also be demonstrated by lymphocyte stimulation tests, although there is some controversy over their usefulness (1). Moreover, little is known about dynamic changes in biomarkers reflecting acute FPIES reactions. Leukocytosis and thrombocytosis have been reported in the acute phase, and the former is included in the diagnostic criteria proposed by Powell (2). These increases likely occur as a result of the secretion of humoral factors including inflammatory cytokines, and may not be specific for FPIES. We therefore investigated changes in fecal markers that could directly reflect gastrointestinal events in acute FPIES reactions.

We studied eight Japanese patients affected with FPIES (Table 1). The diagnosis of FPIES was based on the previously established criteria: 1) repeated exposure to the incriminated food elicits repetitive vomiting and/or diarrhea within $24 \mathrm{~h}$, without any 
other cause for the symptoms; 2) symptoms are limited to the gastrointestinal tract; and 3) removal of the offending protein from the diet results in resolution of symptoms and/or a food challenge elicits vomiting and/or diarrhea within $24 \mathrm{~h}$ after administration of the food (3-5). After making a suspected diagnosis of FPIES, trigger foods were eliminated in all patients. We performed an oral food challenge test in six patients (P1 to P6) in the hospital according to the guideline by Powell et al. (2) and the Japanese guideline for food allergy with minor modifications (6). Briefly, an intravenous line was established before challenge, and oxygen saturation and heart rate were monitored during the procedure. Patients were given the same amount of trigger food that caused the reactions or up to $0.6 \mathrm{~g}$ protein $/ \mathrm{kg}$ body weight. The diagnostic food challenge test was avoided in patients P7 and P8, both of whom had more than three episodes of the typical reactions. Approval for the study was obtained from the Human Research Committee of Kanazawa University Graduate School of Medical Science, and informed consent was provided according to the Declaration of Helsinki.

Fecal samples were collected from patients P1 to P6 before and after the food challenge test. In patients P7 and P8, samples were first collected at their initial visit to our hospital. While planning the challenge test, another episode of FPIES provided us with their fecal samples after accidental ingestion of the causative food. If patients had no spontaneous passage of stool on the next day after the ingestion, glycerin enemas were given. Fecal samples were collected at each defecation during the next 1 to 2 days. Control samples were obtained from 12 age-matched healthy infants. Feces were weighted and diluted 3 to 10 times with phosphate-buffered saline immediately after sample collection or after thawing frozen samples. Homogenization was performed using 
a paddle blender (Interscience, St Nom, France) for 20 min. After centrifugation at 20000 $\mathrm{g}$ for $10 \mathrm{~min}$, supernatants were collected and stored at $-20^{\circ} \mathrm{C}$ until assay. Concentrations of biomarkers were determined using commercially available enzyme-linked immunosorbent assay kits for EDN (MBL, Nagoya, Japan) and calprotectin (Immundiagnostik, Bensheim, Germany). IgA levels were measured by a standard sandwich enzyme-linked immunosorbent assay (7).

The mean age of onset was $5.4 \pm 3.5 \mathrm{mo}$, and the mean time to diagnosis was 3.0 \pm 2.1 mo. The common symptoms were vomiting (8/8), diarrhea (3/8), and lethargy (3/8). Most patients (7/8) developed symptoms $2 \mathrm{~h}$ after the ingestion. All 6 of the patients who underwent the food challenge test exhibited typical reactions of FPIES, which did not differ from their medical history derived from the accidental ingestion of the causative food. Time to symptoms during the challenge test was also similar to those of the accidental ingestion of the causative food in these patients. Consistent with previous reports (1), cow's milk was the most common causative food, followed by wheat. All of our patients reacted to a single food. Two patients (P2 and P6) exhibited positive, albeit low titer, specific IgE results for the causative food (cow's milk); however, no patients had experienced IgE-mediated acute symptoms such as urticaria and wheezing. After elimination of the causative food, no episodes of FPIES were noted in any patient.

Before oral food challenges, mild elevation of fecal EDN levels was observed in 3 of 8 patients. However, these patients did not necessarily show high concentrations of fecal calprotectin and IgA at the same time (Fig 1A). There was no correlation between time to diagnosis and baseline elevations of fecal markers in our patients. In contrast, a significant increase in fecal EDN after ingestion of the causative food was demonstrated 
in all patients (mean, $33244 \mathrm{ng} / \mathrm{mL}$; Fig 1A). The median time to maximum concentration of fecal EDN was $23.5 \mathrm{~h}$. The levels of fecal calprotectin and $\operatorname{IgA}$ were also increased; however, they were much lower than those of EDN (Fig 1B).

The level of EDN was increased a half-day after ingestion and reached the maximum around $24 \mathrm{~h}$ later (Fig 1C). Of note, the elevation of fecal EDN was observed even in non-diarrheal stool specimens. These findings are in line with the Powell's criteria, in which cells and eosinophilic debris are absent in baseline stool smear and present as early as $6 \mathrm{~h}$ after oral food challenges, or as late as the next day (2). Such kinetics may simply reflect intestinal transit time of stool. Accordingly, the levels of fecal EDN may not be sufficiently elevated in samples collected just after ingesting the causative food or at an acute FPIES reaction. On the other hand, levels of fecal EDN before oral food challenges were variable in our patients, which was consistent with a previous report (8). Increased levels of baseline fecal EDN in some patients may be attributable to a direct consequence of previous FPIES episodes or non-specific intestinal inflammation due to previous FPIES episodes. Importantly, such patients also exhibited a further increase in fecal EDN after ingesting the causative food. Taken together, these findings suggest that serial analysis of fecal EDN after ingesting the causative food may serve as a useful diagnostic marker of FPIES. This approach can be used even after accidental ingestion of the causative food in both out-of-hospital and hospital settings. Nevertheless, as this study cohort is small, larger studies will be required to confirm our observations.

Accumulation of eosinophils has been found in intestinal biopsies from patients with FPIES. However, it has been also described in other gastrointestinal disorders such 
as eosinophilic gastroenteropathies, and eosinophils are a normal component of intestinal mucosal tissue. EDN, one of the four major eosinophil granule proteins, is recognized as being involved in antiviral host defense. Neutrophils have been found in stool mucus from patients with FPIES (2). In fact, our patients exhibited increased levels of fecal calprotectin after ingestion of the causative food, albeit at lower levels than fecal EDN. Phagocytes are the main source of fecal calprotectin, which has been reported to be a reliable marker of inflammatory activity in inflammatory bowel diseases (9). These findings suggest that the elevations of fecal EDN and calprotectin are not specific for FPIES. However, dynamic changes in fecal EDN after ingesting the causative food could distinguish FPIES from other inflammatory conditions. In addition, the changes may point to a characteristic component of the immune reaction in FPIES, and provide us an additional tool for evaluating FPIES reactions. Although FPIES is considered to be a Tcell mediated disorder, its immune mechanisms remain to be determined. A recent study has shown that antigen-specific T-cell responses are predominantly skewed to $\mathrm{Th} 2$ in FPIES (10). Thus, further studies will be necessary to elucidate a link between antigenspecific T-cell responses and inflammatory responses including eosinophil activation in FPIES.

In summary, our studies demonstrate a significant elevation of fecal EDN after the ingestion of causative foods and may offer additional perspective on the diagnosis of FPIES. Characterization of fecal markers that reflect inflammatory gastrointestinal conditions would contribute to clarifying the disease pathogenesis of FPIES. 


\section{Acknowledgments}

We thank Ms. Harumi Matsukawa and Ms. Shizu Kouraba for their excellent technical assistance.

\section{Funding}

This work was supported by a Grant-in-Aid for Scientific Research from the Ministry of Education, Culture, Sports, Science and Technology of Japan; and a grant from the Ministry of Health, Labour, and Welfare of Japan, Tokyo.

\section{Conflicts of Interest}

No conflicts of interest declared. 


\section{References}

1 Caubet JC, Nowak-Wegrzyn A. Current understanding of the immune mechanisms of food protein-induced enterocolitis syndrome. Expert Rev Clin Immunol. 2011; 7: $317-27$.

2 Powell GK. Food protein-induced enterocolitis of infancy: differential diagnosis and management. Compr Ther. 1986; 12: 28-37.

3 Sicherer SH, Eigenmann PA, Sampson HA. Clinical features of food protein-induced enterocolitis syndrome. J Pediatr. 1998; 133: 214-9.

4 Nowak-Wegrzyn A, Sampson HA, Wood RA, Sicherer SH. Food protein-induced enterocolitis syndrome caused by solid food proteins. Pediatrics. 2003; 111: 829-35.

5 Mehr S, Kakakios A, Frith K, Kemp AS. Food protein-induced enterocolitis syndrome: 16-year experience. Pediatrics. 2009; 123: e459-64.

6 Urisu A, Ebisawa M, Mukoyama T, Morikawa A, Kondo N. Japanese guideline for food allergy. Allergol Int. 2011; 60: 221-36.

7 Wada H, Horisawa T, Inoue M, Yoshida T, Toma T, Yachie A. Sequential measurement of fecal parameters in a case of non-immunoglobulin E-mediated milk allergy. Pediatr Int. 2007; 49: 109-11.

8 Kalach N, Kapel N, Waligora-Dupriet AJ, et al. Intestinal permeability and fecal eosinophil-derived neurotoxin are the best diagnosis tools for digestive non-IgEmediated cow's milk allergy in toddlers. Clin Chem Lab Med. 2013; 51: 351-61. 
9 Foell D, Wittkowski H, Roth J. Monitoring disease activity by stool analyses: from occult blood to molecular markers of intestinal inflammation and damage. Gut. 2009; 58: $859-68$.

10 Morita H, Nomura I, Orihara K, et al. Antigen-specific T-cell responses in patients with non-IgE-mediated gastrointestinal food allergy are predominantly skewed to T(H)2. J Allergy Clin Immunol. 2013; 131: 590-2 e1-6. 
Table 1 Patient characteristics

$\begin{array}{llllllll}\mathrm{P} 1 & \mathrm{P} 2 & \mathrm{P} 3 & \mathrm{P} 4 & \mathrm{P} 5 & \mathrm{P} 6 & \mathrm{P} 7 & \mathrm{P} 8\end{array}$

\begin{tabular}{|c|c|c|c|c|c|c|c|c|}
\hline Age at onset (mo) & 10 & 0 & 7 & 7 & 6 & 0 & 6 & 7 \\
\hline Age at diagnosis $(\mathrm{mo})^{\mathrm{a}}$ & 16 & 1 & 13 & 11 & 8 & 1 & 8 & 9 \\
\hline Sex & $\mathrm{F}$ & $\mathrm{F}$ & M & M & $\mathrm{F}$ & $\mathrm{F}$ & M & $\mathrm{F}$ \\
\hline Trigger food & Fish $^{b}$ & $\mathrm{CM}$ & Egg & Wheat & Rice & $\mathrm{CM}$ & $\mathrm{CM}$ & Wheat \\
\hline Symptoms & $\begin{array}{l}\text { Vomiting } \\
\text { Lethargy }\end{array}$ & $\begin{array}{l}\text { Vomiting } \\
\text { Pallor } \\
\text { Fever }\end{array}$ & $\begin{array}{l}\text { Vomiting } \\
\text { Lethargy } \\
\text { Diarrhea }\end{array}$ & $\begin{array}{l}\text { Vomiting } \\
\text { lethargy }\end{array}$ & $\begin{array}{l}\text { Vomiting } \\
\text { diarrhea }\end{array}$ & $\begin{array}{l}\text { Failure } \\
\text { to thrive } \\
\text { Vomiting } \\
\text { Bloody } \\
\text { stool }\end{array}$ & $\begin{array}{l}\text { Vomiting } \\
\text { Bloody } \\
\text { stool }\end{array}$ & $\begin{array}{l}\text { Vomiting } \\
\text { Pallor } \\
\text { Diarrhea }\end{array}$ \\
\hline Time to symptoms (h) & 2 & 2 & 2 & 2 & 2 & 8 & 2 & 2 \\
\hline Total IgE (IU/mL) & 5 & 60 & 5 & 28 & 22 & 15 & 42 & 111 \\
\hline Specific $\operatorname{IgE}{ }^{c}$ & fish (0) & $\begin{array}{l}\beta \text {-LG (2) } \\
\text { milk (1) } \\
\operatorname{casein}(1)\end{array}$ & $\operatorname{egg}(0)$ & $\begin{array}{l}\operatorname{egg}(3) \\
\text { wheat (0) } \\
\text { gluten (0) }\end{array}$ & $\begin{array}{l}\operatorname{egg}(2) \\
\text { rice }(0)\end{array}$ & milk (1) & $\begin{array}{l}\text { milk }(0) \\
\text { casein }(0) \\
\beta-L G(0)\end{array}$ & $\begin{array}{l}\text { egg }(1) \\
\text { wheat (0) } \\
\text { gluten (0) }\end{array}$ \\
\hline
\end{tabular}

CM, cow's milk; $\beta$-LG, $\beta$-lactoglobulin. ${ }^{\text {a }}$ Age of confirmed diagnosis by the challenge test (P1 to P6) or by clinical assessment (P7 and P8). ${ }^{\mathrm{b}}$ Sebastes alutus. ${ }^{\mathrm{c}}$ Numbers in parentheses indicate specific IgE class. 


\section{Figure Legend}

Figure 1 Analysis of eosinophil-derived neurotoxin (EDN), calprotectin and IgA. A, Fecal markers were measured in patients with FPIES before and after the ingestion of the causative food. Shaded areas represent the ranges of the normal values. B, Ratio between before and after the ingestion. C, Kinetics of fecal EDN. Analysis of differences among groups was performed using the Student's $t$-test and differences with $p$-values less than

0.05 were considered significant. ns, not significant. ${ }^{*} p<0.05 ; * * p<0.01 ; * * *<0.001$. 


\section{Figure 1}
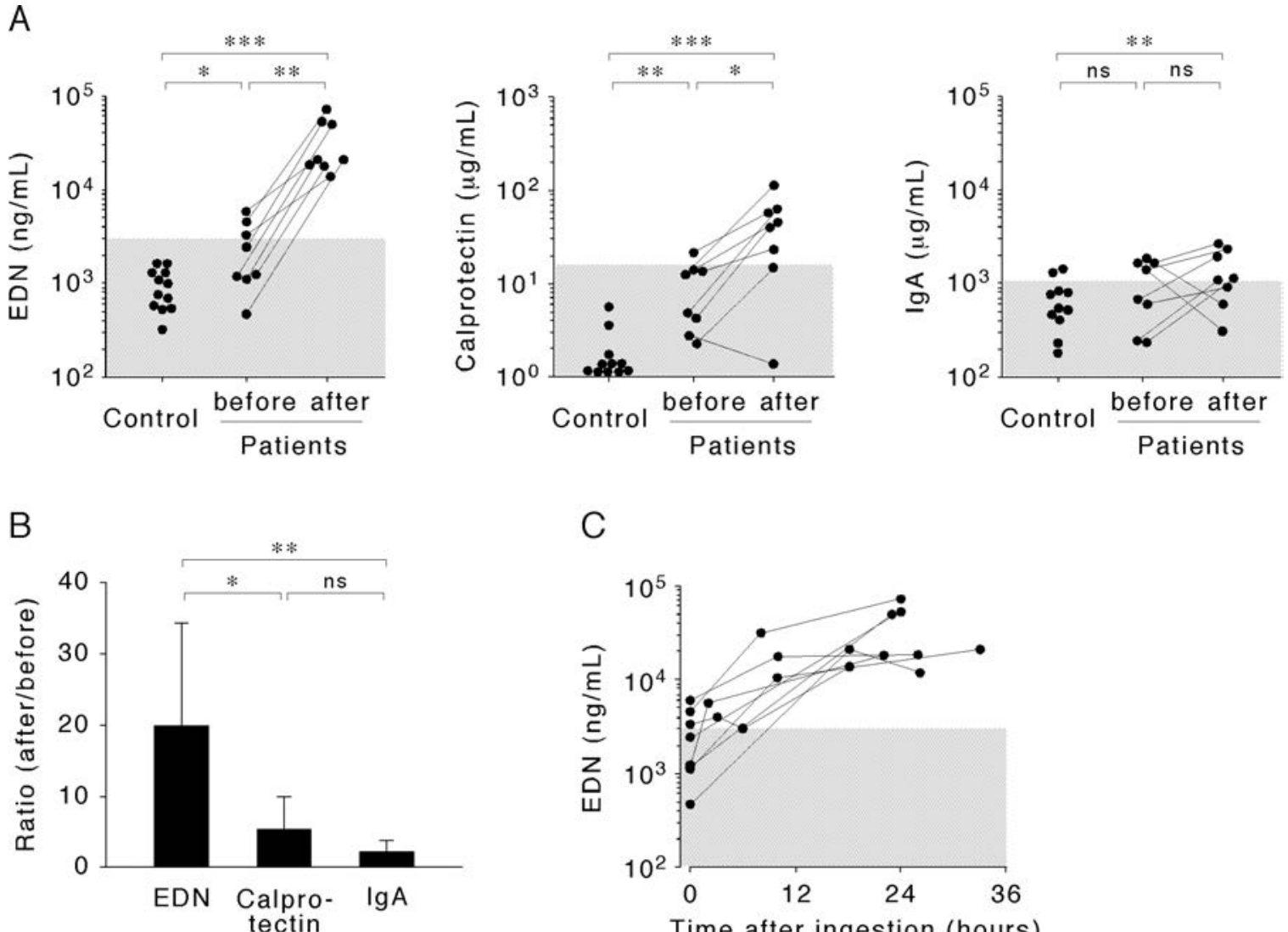

C

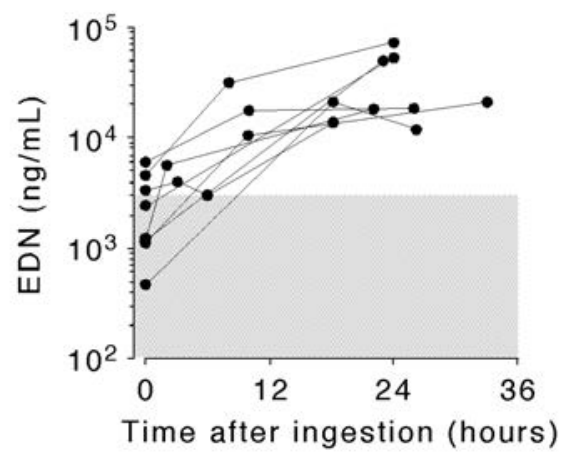

